\title{
ГЕОЛОГИЯ
}

\section{НОВЫЙ ВЗГЛЯД НА ПОЛЕВЫЕ МЕТОДЫ ВЫСОКОТОЧНЫХ ГРАВИРАЗВЕДОЧНЫХ РАБОТ В КОМПЛЕКСЕ ГЕОФИЗИЧЕСКИХ МЕТОДОВ РАЗВЕДКИ}

\author{
Е.Н. Волкова, Д.А. Барулин, В.А. Исаев, В.И. Щепотьев \\ Саратовский государственный университет, \\ кафедра геофизики \\ E-mail: volkovaen@info.sgu.ru
}

Предлагаемая статья представляет материалы, наглядно демонстрирующие отображение в поле $\Delta g$ малоамплитудных разрывных нарушений, слабо ощущаемых в волновом поле, и проявление амплитудной неустойчивости кривых $\Delta g$, отражающее особенности «тонкой структуры» гравитационного поля, которые можно трактовать как связанные с потенциальной нефтегазоносностью объектов.

Цель статьи - обратить внимание недропользователей на необходимость проведения высокоточных гравиметрических, а еще лучше гравимагнитных наблюдений на сейсморазведочных профилях по совмещенной схеме.

New View at Field Methods of Precision Graviprospecting Works in the Complex of Geophysical Methods of Investigation

E.N. Volkova, D.A. Barulin, V.A. Isaev, V.I. Shchepotev

The paper represents materials which evidently show small amplitude faults in the gravitational field, poorly seen in a wave field, and appearance of peak of instability among $\Delta g$ curves reflecting features of «thin structure» of the gravitational field which can be considered as objects potentially containing oil and gas. The purpose of this paper is an attraction of attention of users of subsoil resources on necessity to carry out precision gravimetric or even better to do gravimagnetic investigations along seismic profiles using combined scheme.

В известной публикации главного редактора журнала «Геофизика» О.К. Кондратьева [1] предлагается «новая парадигма» комплексирования геофизических методов, в которой традиционная стратегия проведения вначале рекогносцировочных (региональных) работ более легкими и дешевыми геофизическими методами (гравиразведка и магниторазведка), основанная на классическом принципе стадийности, заменяется новой стратегией, идущей от сейсморазведки. Кондратьев пишет: «... сейсмические работы должны быть опережающими в общем комплексе. Они должны выявлять и готовить объекты по месту их положения для последующих работ по определению веществен-

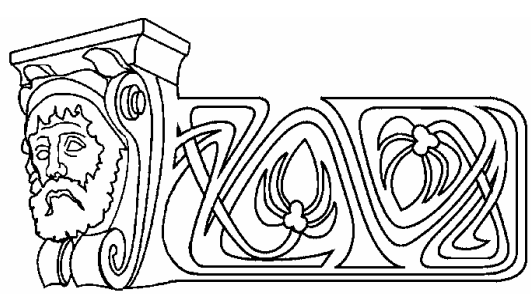

ного состава или состояния среды $<\ldots>$ Перед высокоточной гравиметрией, а также магнитометрией надо прежде поставить задачи изучения покрывающей толщи пород, выявления в ней субвертикальных неоднородностей и расширения числа разнородных осредненных характеристик пород, учитываемых при построении приближенной к реалиям общей геофизической модели среды. Такая задача может показаться малозначимой, однако это не так. Все плохо учтенные особенности верхней части разреза, через которую проходит сигнальное сейсмическое или электромагнитное поле, в той или иной степени неизбежно переносятся на относимые к глубоким слоям параметры среды. При решении достаточно тонких геологогеофизических задач, находящихся на грани физических возможностей наших методов, это совсем немаловажная деталь» [1].

Тем самым на интегральные, подверженные в наибольшей степени проявлениям теоретической и практической эквивалентности, геопотенциальные методы «возлагается» существенная критериальная нагрузка по выбору оптимальных вариантов сейсмической интерпретации, наилучшим образом отвечающих совокупности различных геолого-геофизических данных. Причем сюда могут быть включены и неструктурные аспекты интерпретации вплоть до прямого прогнозирования нефтегазоносности объектов, выявленных сейсморазведкой. Принципиальные возможности такого прогнозирования установлены еще в 60-х гг. прошлого столетия, а за последние годы появилось немалое число работ, где эти возможности нашли убедительное практическое подтверждение [2]. 
К сожалению, практика современной геофизической разведки базируется исключительно на сейсморазведочных работах. Гораздо реже проводятся электроразведочные, а грави- и магниторазведка практически не ведутся уже более 10 лет. По крайней мере, такая ситуация сложилась в Нижнем Поволжье, где, по свидетельству авторов [3, 4], данные этих методов сохраняют лишь фондовое значение.

В работе [4] приведены примеры эффективного привлечения гравимагнитных материалов при решении задач выявления перспективных участков для постановки детальной сейсморазведки, локализации объектов поиска, построения согласованных сейсмогравимагнитных физико-геологических моделей (ФГМ). Однако ни в этой, ни в других публикациях не было представлено данных, наглядно демонстрирующих отображение в поле $\Delta g$ малоамплитудных разрывных нарушений, слабо ощущаемых в волновом поле, a также проявление амплитудной неустойчивости кривых $\Delta g$, отражающих особенности «тонкой структуры» [5] гравитационного поля, которые можно трактовать как связанные с потенциальной нефтегазоносностью объектов.

Цель предлагаемой статьи как раз и состоит в том, чтобы такие данные представить и тем самым еще раз обратить внимание недропользователей на необходимость проведения высокоточных гравиметрических, а еще лучше гравимагнитных наблюдений на сейсморазведочных профилях по совмещенной схеме. Когда-то проведение таких работ способствовало открытию крупнейших скоплений углеводородов на юго-востоке бортовой зоны Прикаспийской впадины (работы ОАО «Саратовнефтегеофизика» на Тенгизском и Королевском объектах), сейчас такие работы, но с более плотной системой наблюдений, по нашему мнению, необходимо вести на небольших объектах Волго-Уральской провинции.

Целью проведения высокоточных гравиметрических работ на территории правобережья Саратовского Поволжья (Курдюмский лицензионный участок) являлось уточнение геологического строения структур, выявленных в процессе сейсморазведочных работ, и локальный прогноз нефтегазоноснос- ти данных объектов. Высокоточные гравиметрические работы проведены по сейсмическим профилям общей протяженностью 80 пог. км.

Наблюдения выполнялись по однократной методике с применением опорной сети двумя гравиметрами ГНУ-К/1 с инструментальной погрешностью 0,03-0,05 мГал. Контрольные наблюдения составили $10 \%$ от общего числа точек. Расстояние между точками наблюдения 100 м. Методика анализа геофизических материалов включала компьютерную обработку полевых данных с введением стандартных редукций и вычисление прямых гравитационных эффектов.

В результате выполненных работ составлены кривые изменений значений поля силы тяжести в редукции Буге. Сформированы также сейсмогравиметрические модели исследуемых объектов в профильном варианте, вычислены гравиметрические эффекты от геологических структур предполагаемого девонского возраста.

Высокоточная гравиразведка, проведенная на территории Курдюмского лицензионного участка, выявила несколько важных и неоспоримых преимуществ по отношению к региональной (площадной) съемке, проведенной ранее практически повсеместно и захватившей в том числе изучаемую территорию. Сопоставление графиков аномалий силы тяжести в редукции Буге по отработанным профилям и графиков, построенных на основе карт масштаба 1:50000, составленных ранее, показало, что наблюдается лишь общее соответствие характера аномалий.

Площадная съемка позволяет получить аномалии, в большей мере отображающие влияние объемных масс и дать более обоснованную геологическую интерпретацию в «региональном» масштабе. Объяснить это можно тем, что при составлении карт принято проводить изоаномалы в пределах утроенной величины среднеквадратической ошибки определения аномалий силы тяжести (в лучшем случае в пределах единичной величины). Поэтому часто узколокальные аномалии небольшой интенсивности на картах теряются. Локальные же «всплески», характеризующие разрывные нарушения, при пятидесятитысячной съемке (с шагом между пикетами наблюдений 250 м) фиксируются су- 
щественно реже, чем при высокоточной (профильной), а в случае их присутствия они, как правило, просто отбраковываются.

В качестве примера можно привести профиль № 7 (рис. 1), сравнительная характеристика которого по данным профильной и площадной съемки показывает, что обобщенная, «региональная» структура гравитационного поля участка ПК 35-50 соответствует поднятию по глубоким горизонтам (девонские отложения), осложненному разрывными нарушениями, которые проявляются только на графике высокоточной профильной съемки.
На рис. 2 представлен другой пример (профиль № 20A). Резкий «всплеск» аномалии выявляет сброс амплитудой более 100 метров. По данным площадной съемки, мы не видим даже элементов этого высокоамплитудного разлома. Очевидно, что высокоточная съемка наряду с «региональной» компонентой содержит в себе локальные составляющие, отображающие более мелкие геологические объекты (антиклинальные структуры, в том числе малоамплитудные, останцы в фундаменте, рифогенные тела, разрывные нарушения и др.).

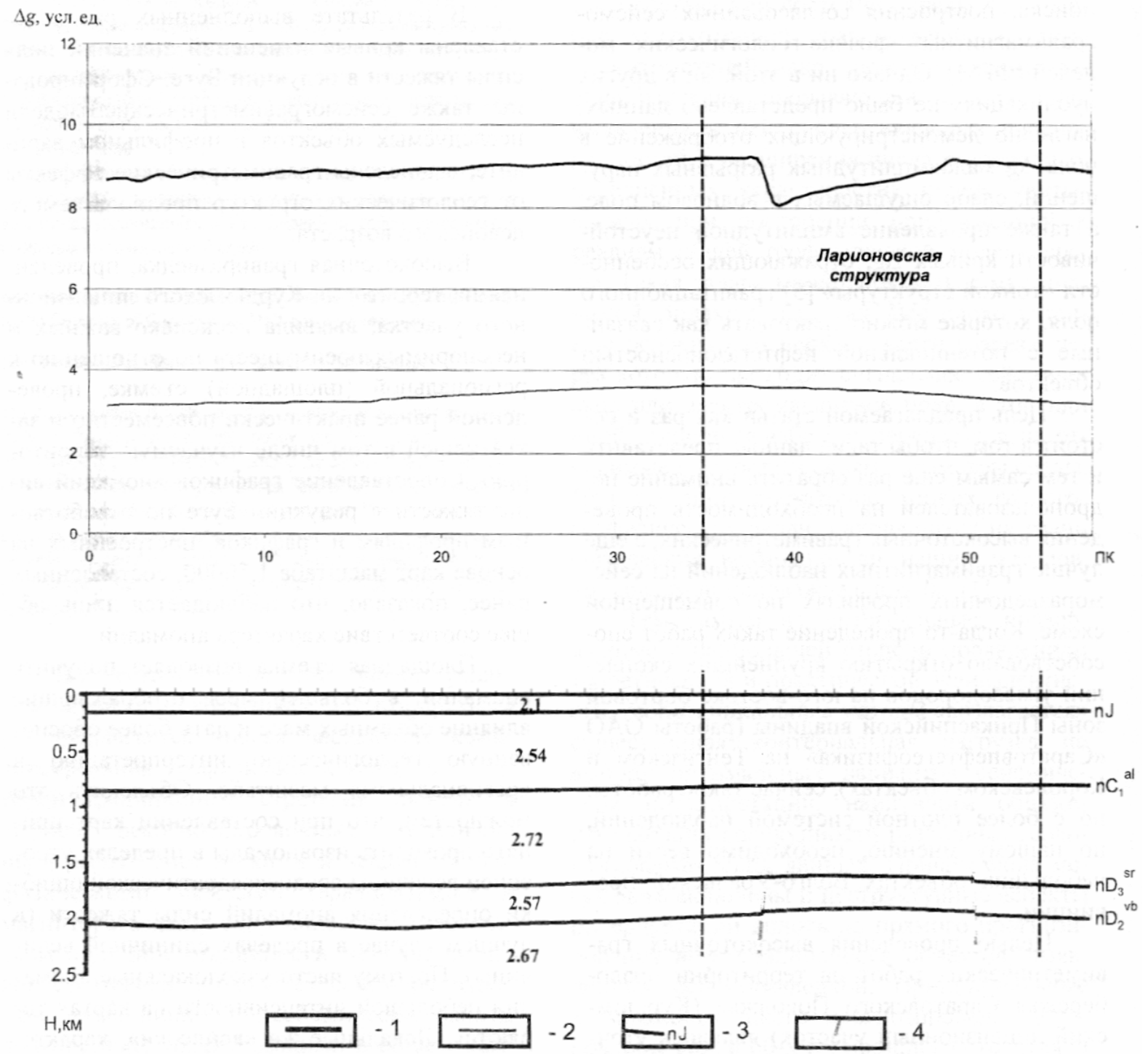

Рис. 1. Геолого-геофизическая модель профиля № 7: 1 - наблюденные аномалии $\Delta g$, высокоточная съемка; 2 - наблюденные аномалии $\Delta g$, региональная съемка; 3 - отражающие горизонты; 4 - линии разломов по данным сейсморазведки 


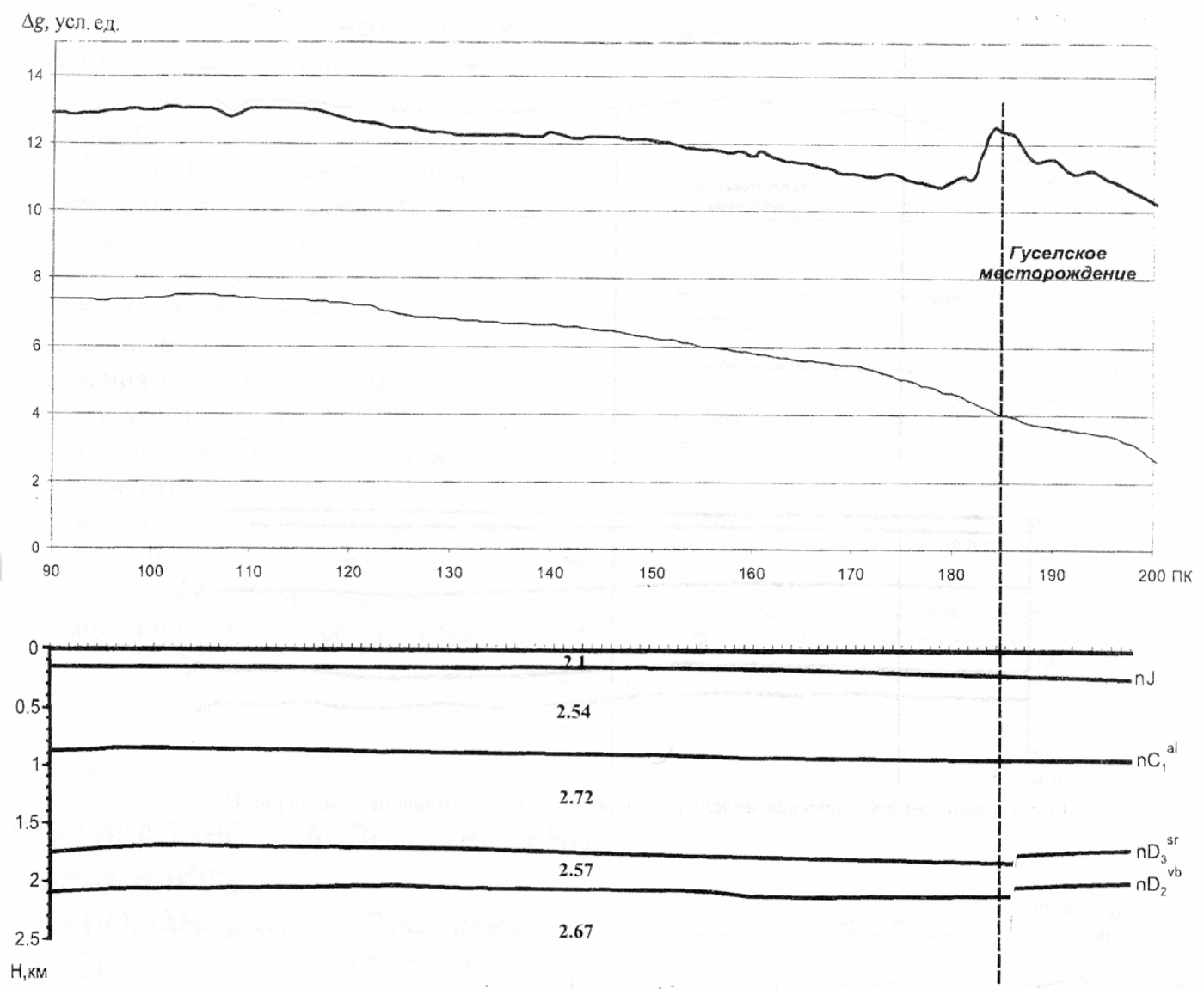

Рис. 2. Геолого-геофизическая модель профиля № 20А (усл. обозначения см. на рис.1)

Что касается влияния скопления углеводородов (залежей нефти и газа), то они обычно находят отражение в поле $\Delta g$ в виде локального уменьшения значений аномалий [2]. Кроме того, залежи УВ возможно фиксируются фрагментами кривой $\Delta g$ с повышенной дисперсией, которую можно зарегистрировать только при небольшом шаге между пикетами. Например, можно отметить такую высокочастотную составляющую в районе Харламовской структуры, выявленной по данным сейсморазведки (профиль № 20 (рис. 3)). Здесь на участке ПК 25-45 в наблюденном поле $\Delta g$ фиксируется высокочастотная запись с повышенной дисперсией, которая, возможно, свидетельствует о наличии скоплений УВ. Причем очевидно, что шаг между пикетами в 100 метров слишком велик. Чтобы уловить такие тонкие эффекты, необходимо уменьшить эту величину до 20-25 м и тем самым зафиксировать в полной мере особенности «тонкой структуры» поля $\Delta g$.
Выполненные высокоточные гравиметрические работы на изучаемой территории позволили также выявить ряд объектов, не нашедших отображения на сейсмических профилях, т.е., вероятнее всего, потерянных в результате обработки либо в процессе интерпретации сейсмических данных. В качестве примера можно привести профиль № 16 (рис.4), где, по сейсмическим данным, почти не отмечается каких-либо аномалий, тогда как на гравиметрической кривой видно присутствие двух зон, возможно, связанных с разрывными нарушениями разной амплитуды.

Таким образом, становится ясным, что данные высокоточной гравиметрической съемки вполне возможно и даже необходимо привлекать при уточнении данных сейсморазведки (как это не парадоксально звучит), а также, вероятно, и для прямого прогнозирования наличия залежей УВ на структурах, выявленных в процессе проведения сейсморазведочных работ. Впрочем, последнее ут- 

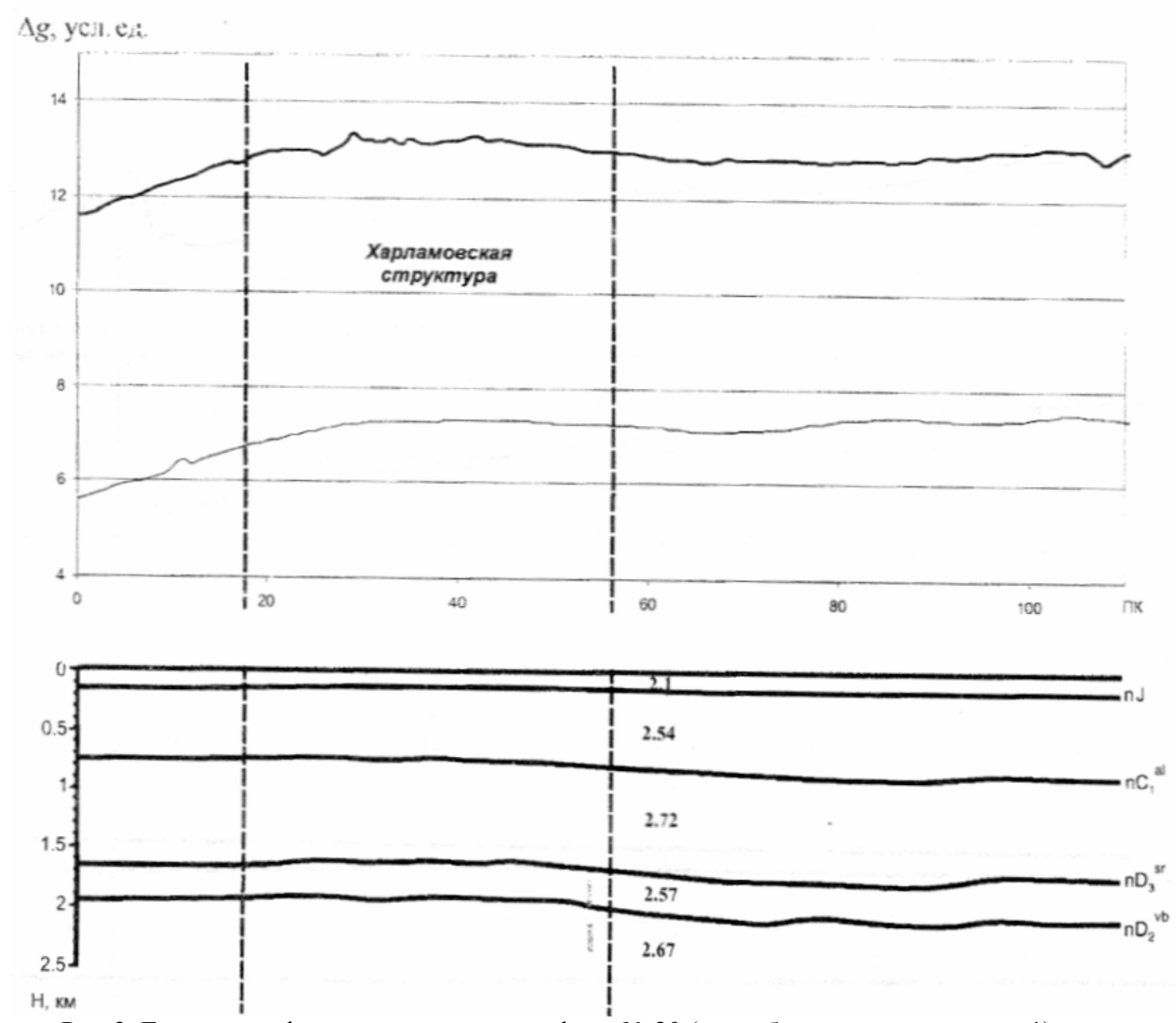

Рис. 3. Геолого-геофизическая модель профиля № 20 (усл. обозначения см. на рис.1)

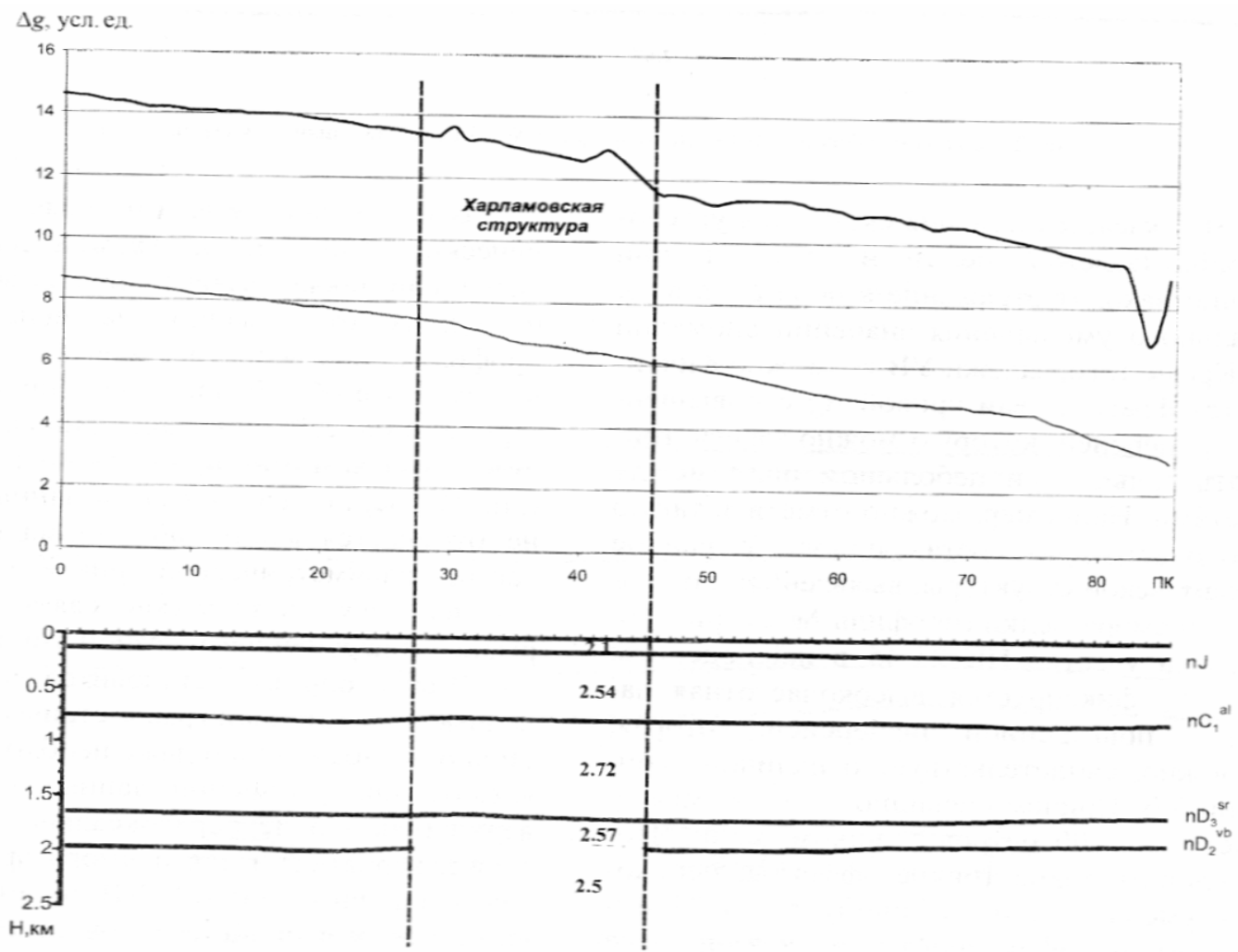

Рис. 4. Геолого-геофизическая модель профиля № 16 (усл. обозначения см. на рис.1) 
верждение еще нуждается в проверке последующим бурением. Вполне возможно, что подобные исследования где-то уже имели место, но не нашли должного освещения в литературе.

Возвращаясь к началу нашей статьи, заметим, что стратегия, предлагаемая О.К. Кондратьевым, одним из самых влиятельных теоретиков и практиков геофизической разведки, имеет все основания для становления в качестве руководящей парадигмы комплексирования геофизических методов на современном уровне их развития. Наилучшим вариантом ее реализации, по нашему мнению, является отработка сейсмических профилей высокоточными (с шагом 25-100 м) гравиметрическими или гравимагнитными наблюдениями с последующей совместной интерпретацией по методике согласованной ФГМ
Авторы признательны профессору кафедры геофизики М.И. Рыскину за консультации при подготовке материалов статьи.

\section{Библиографический список}

1. Кондратьев О.К. Физические возможности и ограничения разведочных методов нефтяной геофизики // Геофизика. 1997. №3.

2. Чернов А.А., Колесов В.В. Обнаружение и картирование залежей УВ по их проявлениям в геопотенциальных полях // Геофизика. Спец. вып. «Пангее 10 лет». 2004.

3. Конценебин Ю.П., Рыскин М.И., Сокулина К.Б. О необходимости проведения повторных гравимагнитных съемок в Саратовском Поволжье // Недра Поволжья и Прикаспия. 2004. Вып. 35.

4. Рыскин М.И., Сокулина К.Б., Барулин Д.А. Об эффективности комплексирования сейсмических данных с гравиметрическими при разведке нефтегазоперспективных объектов // Геофизика. 2005. №4.

5. Витвичкий O.B. Некоторые приложения теории катастроф к гравиметрии // Математика и геофизика. М., 2000. 